\title{
Emotional health: on the applicability of affective science to the integration of clinical psychology
}

\author{
Ewa Trzebińska ${ }^{E, F, G}$ \\ University of Social Sciences and Humanities, Warsaw, Poland
}

The aim of the article is to outline the concept of emotional health and its integrative potential in the field of clinical psychology. It is a well-known fact that the transdiagnostic approach and psychotherapy integration - the two most influential integrative movements in clinical psychology - search for a sound conceptual foundation of the efforts to organize a plethora of theories and data relating to the psychological aspects of physical and mental health. Following a short presentation of general discrepancies af- flicting clinical psychology and the main ideas of both the transdiagnostic approach and psychotherapy integration, the notion of emotional health is introduced and its unifying convenience, as well as limitations, is discussed.

KEY WORDS

emotions; transdiagnostic processes; psychotherapy integration

CORRESPONDING AUthor - Prof. Ewa Trzebińska, SWPS University of Social Sciences and Humanities,

19/31 Chodakowska Str., 03-815 Warsaw, Poland, e-mail: ewa.trzebinska@swps.edu.pl

AUthors' CONTRIBUtion - A: Study design - B: Data collection - C: Statistical analysis - D: Data interpretation .

E: Manuscript preparation · F: Literature search · G: Funds collection

TO CITE THIS ARTICLE - Trzebińska, E. (2017). Emotional health: on the applicability of affective science to the integration

of clinical psychology. Current Issues in Personality Psychology, 5(3), 172-182.

RECEIVED 19.05.2017 · REVIEWED 03.07.2017 · ACCEPTED 13.07.2017 • PUBLISHED 22.09.2017 


\section{THE NEED FOR INTEGRATION IN CLINICAL PSYCHOLOGY}

The dispersion within the area of clinical psychology has several facets. The most fundamental among them is the well-established view of mental health that separates psychopathology and good mental health as two qualitatively different aspects of human functioning, with distinctive procedures of diagnosis and intervention involving mental disorders and well-being. Additionally, according to the traditional classification based on symptoms and exact thresholds of psychopathology, various mental disorders are also viewed as totally independent entities, despite the fact that they share symptoms, co-occur, rarely appear in entirely "pure" forms, and the same interventions are effective for many of them (Kring \& Mote, 2016). Since mental disorders are diagnosed on the basis of the occurrence of a relatively small part of the clusters of assigned symptoms, great variance of diagnosed disorders is observed, i.e. patients presenting quite different sets of functional abnormalities receive the same diagnosis (Eaton, Rodriguez-Seijas, Carragher, \& Krueger, 2015). On the other hand, due to the lack of continuity in the functional normality versus abnormality concept, persons with functional abnormalities which are only slightly above the psychopathology threshold are diagnosed with mental disorders regardless of their apparent similarity to those categorized as healthy.

The other integration problems are the more or less remote consequences of the first one. There is a gap between diagnosis and therapy, because disorder oriented diagnosis has little use for interventions intended for causal improvement. The empirically supported treatment approach (EST) multiplies treatment protocols because, according to the rules, there is an obligation to prepare specific protocols for each treatment and each disorder involved (Laska, Gurman, \& Wampold, 2014). These two core assumptions, about treatment specificity and disorder specificity, cause the EST paradigm to generate a multitude of separate protocols, despite the fact that treatments targeting different mechanisms of change together can be more efficacious in curing multi-symptom conditions than each of them alone, and that the treatment for a particular symptom can also be effective in curing different disorders sharing that symptom. The communication between psychological science and clinical practice is weak, as research is concerned with explaining functional deficiency and well-being, while diagnosis and therapy are concerned mainly with symptoms and mental disorders. Psychology of mental and physical health are quite remote fields, regardless of the commonalities in the etiology of both kinds of health problems and their ubiquitous co-occurrence. Mental health is analyzed predominantly as psychopathological symptoms and classified disorders, while the psychological aspects of physical health are analyzed at the level of the involved processes. Similarly, youth and adult health problems are different areas of clinical theory and practice, despite common underlying factors and their continuality across the life span. In the effort to break through these problems, two wellknown integrative movements in clinical psychology emerged: the transdiagnostic approach and psychotherapy integration.

\section{TRANSDIAGNOSTIC APPROACH}

The primary aim of the transdiagnostic approach is to overcome some of the clinical psychology divisions by loosening the rigid rules of the traditional categorization of mental disorders. That aim is achieved by shifting the focus from mental disorders as separate entities to common processes across different disorders that serve to maintain or worsen their symptoms. That new diagnostic perspective can reduce the problem of comorbidity of traditionally diagnosed disorders and inform interventions towards health processes, i.e. the causes of malfunctioning or well-being, no matter whether they involve the body or the mind. The very first account of identifying commonalities between disorders was the well-known dimensions of exteriorization and internalization (Achenbach \& Edelbrock, 1978), which turned out to differentiate two broad categories of psychopathology. That model of two transdiagnostic factors evolved over time into three-factor models (Eaton, Rodriguez-Seijas, Carragher, \& Krueger, 2015). One of them includes externalization, internalization and a new factor of psychosis, while another contains externalization and two new factors originating from internalization: fear and distress. Subsequently, numerous other common psychopathology factors were proposed (Harvey, Watkins, Mansell, \& Shafran, 2004) in cognitive processes (such as disruptions in attention, memory and reasoning) and in behavior (such as avoidance or sexual dysfunctions). As the number and heterogeneity of transdiagnostic factors is still growing, there emerge integrative models explaining their interconnections and specific roles on different paths towards psychopathology, e.g. the categorization of transdiagnostic factors into distal and proximal causes of symptoms, and moderators between proximal causes and symptoms (Nolen-Hoeksema \& Watkins, 2011).

The recent advance in transdiagnostic classification is the Research Domain Criteria (RDoC), a research framework created by the US National Institute of Mental Health as a "road map" intended to guide a summary of already available data and further systematic investigation in neuroscience, 
genetics and psychology, on neurobiological, psychological and behavioral mechanisms that underlie real facts of malfunctioning, including psychopathological symptoms, rather than the made-up categories of mental disorders (Cuthbert, 2014). The RDoC approach promotes multiple units of analysis (including genes, molecules, cells, circuits, physiology, behavior and self-report), across the domains of: (1) negative valence systems, (2) positive valence systems, (3) cognitive systems, (4) social processes, and (5) arousal/regulatory systems. As additional variables, the social and developmental phenomena are recommended to be included in the studies' agenda. That research strategy assumes dimensional nature of mental health with a full range of variation, from normal to abnormal facts about fundamental mental health components (i.e. typical versus bizarre), as well as equal importance of all the units and domains of analysis.

Besides the broad appreciation for systemic and consequent transdiagnostic position, the $\mathrm{RDoC}$ is criticized for the inadequacy of the list of domains of transdiagnostic factors, which overlap at the level of units (e.g. brain circuits) and are incomplete (e.g. lacking in the domain of dispositional traits), for fragmentation of analysis into separate units and domains without any rules how to synthesize the data into a comprehensive picture of mechanisms underlying the symptoms, for an ambiguous relationship between the proposed new paradigm and the old one, for the lack of precise definitions of domains and included variables, and for leaving out physical health problems (Kring \& Mote, 2016; Watson, Stanton, \& Clark, 2016). Those defending the RDoC argue that the most innovative and promising part of the project is the idea of multidisciplinary study identifying in detail real mental health phenomena, so the possibility to alternate the RDoC matrix of domains and units, e.g. to redefine the already included elements or add new ones, is entirely open (Cuthbert, 2014).

\section{PSYCHOTHERAPY INTEGRATION}

The movement of psychotherapy integration is a reaction to the emergence of hundreds of different psychotherapy methods. Any particular method is naturally focused on the limited scope of concepts and problems, and neglects other. Thus, it seems reasonable to exchange between methods some useful ideas and techniques. The aim of the integrative approach is then to strengthen the practice of psychotherapy by identifying the most efficient agents of therapeutic improvement and providing the adequate principles of incorporating them into different methods and even eventually combining convergent or complementary methods into new psychotherapy systems. Integration in psychotherapy can be traced back to the 1930s, since when bridges between psychoanalysis and behavior therapy have been sought, subsequently encompassing many other methods and approaches. It has changed from the eclectic use of techniques belonging to different methods, through searching for conceptualizations that can guide a more systematic and theoretically grounded combination of techniques from different methods, to the most advanced goal of unifying psychotherapy into universal models based on the general theory of psychopathology, treatment and change (Fernández-Álvarez, Consoli, \& Gómez, 2016).

However, after dismissing technical eclecticism as too messy and disappointment with general theories of psychotherapy as always not comprehensive enough, currently the most promising solution seems to be the common factors approach, which relies on empirically identified aspects of psychotherapy shared by all methods that explain therapeutic improvement (Laska, Gurman, \& Wampold, 2014). Despite vital diversity in theories of mental health and treatment, all methods of psychotherapy are proven to be efficient and in that respect close enough, which means that their effects result more from their commonalties than specificity. A variety of factors, such as catharsis, advice, cognitive mastery, exposure to critical emotional experience, feedback, insight, reassurance, mitigation of isolation, success experiences, therapeutic alliance, therapist's expertise, trust, variety of affective experiencing, new emotional experiences, empathy, confronting and resolving emotional ambivalence have been empirically identified as potentially common, curative aspects of psychotherapy (Laska, Gurman, \& Wampold 2014; Brown, 2015). Although the reality of common factors in psychotherapy as well as their restorative impact seems unquestionable on the basis of empirical data, which satisfies the EST's requirements, as critics argue, the common factors approach needs serious conceptual integrative work itself because the catalog of common curative aspects of psychotherapy is too extended and profoundly inconsistent at the theoretical level (Lambert \& Ogles, 2014).

\section{EMOTIONAL HEALTH}

The transdiagnostic approach and the integration of psychotherapy are expansive professional movements and have a significant impact on the development of concrete practical solutions as well as on the overall handling and understanding of health problems at the theoretical and scientific ground. As they originated in different fields of clinical practice, they have been expanding rather independently so far, but the need for their alliance is becoming evident, which can be seen in the example of some practical junctions such as the emergence of various "unified 
treatment protocols" (Laska, Gurman, \& Wampold, 2014). Since both the transdiagnostic approach and integration of psychotherapy are concerned with health-related interpersonal and psychological processes, the fusion of their objectives could benefit from a common theoretical model of those processes. While no general theory of mind is available at the present time, the medium-range concepts can be of use. As affective processes constitute a large part of transdiagnostic factors and common psychotherapy factors, the notion of emotional health comes to mind (Trzebińska, 2012).

Affective science is a field of multidisciplinary study of all possible forms of affective phenomena and explains them at psychological, physiological, neural, and genetic levels of the human organism in the effort to gain a consistent perspective on the specificity of the affective appraisal. A large part of affective science achievements focuses on emotions, i.e. the most comprehensive form of affective appraisal, a phenomenon whose adaptivity determines human mental and physical wellness to a great extent. Taken together, these data can form a concept of emotional health.

There are several reasons to address the concept of emotional health in the context of integration within the domain of clinical psychology. First, emotions play a prominent role in practically all mental and physical processes. They are emergent mental states which arise from the activity of the complex allostatic brain system facilitating the most appropriate response to the momentary demands and opportunities, composed as sets of various bodily and mental changes. Emotion starts with a core affect - the brain response to a salient negative or positive stimulus - which is the basic building block of emotional processing (Genzel, Rarick, \& Morris, 2016), followed by the crucial substrate of the feeling, i.e. a conscious experience of emotion (Barrett, 2005). The core affect is accompanied by physiological, psychological and behavioral components organized into a coherent and complete whole, partly by situational circumstances, partly by innate affective programs, and partly by cultural concepts of emotions (Clore \& Robinson, 2012). The affective workspace system in the brain, which is viewed as the generator of the core affect, appears to be connected to all other networks in the brain; therefore emotions engage countless non-emotional psychological processes and thus are considered to be primary to the entire mental activity (Clark-Polner, Wager, Satpute, \& Barrett, 2016), and to determine health by shaping physiological responses, guiding health-related knowledge, attitudes, decisions and behavior (DeSteno, Gross, \& Kubzansky, 2013; Tryon, 2016). Accordingly, the most effective strategy of initiating major improvement in a person's functioning with respect to health seems to be the correction of faulty emotional processing first (Trzebińska, 1998; Epstein \& Epstein, 2016; Hofmann, 2016).

Second, emotions are highly functional, but can also be dysfunctional. Emotions relate to attainment of personal and social goals as they reflect successes, failures or anticipations of both, and motivate a person to change or maintain relations between the organism and the environment depending on their meaning for the goals' achievement (Thompson \& Winer, 2013; Fisher \& Manstead, 2016). From that point of view emotions may be seen as states of action readiness (Frijda, 2008), but they influence functioning indirectly via information more often than directly via behavioral activation (Clore \& Robinson, 2012). Particular emotions (such as fear, sadness, joy, shame, pride, nostalgia) arise in specific circumstances for the sake of specific adaptive purposes. However, in the case of inadequate emotional generation or emotional regulation, resulting emotional states can cause suboptimal action or harm (Frijda, 2008).

Third, the level of emotional maturity allows one to predict health problems and thus set goals and procedures of psychological prevention or intervention. The character of emotional processing changes during the life span. There is a firm genetic base of affectivity, mainly in reactivity to signs of threat (negative affectivity) and signs of reward (positive affectivity) which, together with cognitive development, real life emotional experiences and social training, form a personal style of emotional functioning (McAdams, 2016). The human baby has an inborn capacity for several types of elementary affective responses to universal problems concerning survival and nurture - called action patterns or, more traditionally, primary emotions - but growing cognitive abilities and social training allow for the widening of emotional processing and increasingly experiencing more complex emotions and a more diverse scope of emotions (Lewis, 2016). As emotional life becomes more mature in that sense, its functions expand and are performed more effectively; thus the person grows to be more and more emotionally competent, which promotes happiness and flourishing. On the other hand, emotional shortcomings resulting in lowering of any aspect of the quality of life are omnipresent in all categories of psychopathology and underlie a number of medical conditions. Since there is an apparent genetic contribution to the potential for emotional maturation (Nikolova, Davis, \& Hariri, 2016), the genetic background of emotional processing can, to some extent, explain the heritability of mental and physical health problems, and a certain emotional deficiency can limit the scale of cure. On the other hand, the principles of emotional development through social learning and emotional training can explain the health problems in the context of familial factors and life events, and can be applied in psychological diagnosis and interventions. 
Fourth, the plasticity of emotional processing allows one to improve health through the procedures of emotion modification. Emotional processing is constantly adapting to external circumstances and personal goals (Suri \& Gross, 2016), as well as to specific emotional requirements, such as the meta-emotions (i.e. emotions elicited by experienced emotions; Shaver, Veilleux, \& Ham, 2013) or the ideal affect (i.e. emotional states which an individual regards as right and wants to feel; Tsai \& Park, 2014). Consequently, emotional regulation is continuously occurring as the emotion evolves and engages the same processes as emotion generation (Clark-Polner, Wager, Satpute, \& Barrett, 2016). There is a lot of empirical data describing strategies of emotion regulation and explaining determinants of its effectiveness (Suri \& Gross, 2016), which enhance the extent and accuracy of evaluation of health premises and inform professional techniques strengthening health via altering emotional processing. In fact, practically all psychotherapeutic modalities use techniques of that kind.

The terms "emotional health" and "social-emotional health" are widely used already as a more benign expression for "mental health", especially in reference to youth (e.g. You, Furlong, Felix, \& O’Malley, 2015) or nonclinical populations (e.g. Renshaw, Eklund, Bolognino, \& Adodo, 2016; Brown, Larson, Harper, \& Holman, 2016). They are often applied in the case of affective disorders in particular, but also as synonymous with good mental health in general and, more narrowly, as synonymous with a high level of happiness or low level of distress (e.g. Mernitz \& Kamp Dush, 2015). However, all these uses of the term "emotional health" seem inaccurate because the emotion-health connection appears to be much more complex and multi-faced. Relatively similar to the proposed notion of emotional health is the concept of emotional capital that is conceived as a component of social capital and refers to the set of a few emotional competencies promoting personal growth and successes, as well as social productivity and cohesion (Gendron, Kouremenou, \& Rusu, 2016). Although still not complete from the point of view of affective science and not concerned explicitly with health, the concept of emotional capital is in line with the proposed concept of emotional health because of the integrative character of both and their explanatory and anticipatory potential.

Emotional health can be defined by a set of parameters of affective processing with empirically established optimal values referring to various forms of health. The closer to the optimal value on a higher number of parameters, the better is the emotional health. On the basis of current data we can list numerous emotional health parameters. The multitude of emotional health parameters can be organized into seven categories.

Emotional valence. Valence refers to the affective dimension of emotions. Both positive and nega- tive affects have momentary and long-lasting health consequences. Positive affect promotes cognitive expansion, behavioral flexibility and physiological suppression of cardiovascular reactivity caused by negative emotions, which instantly reduce stress, facilitate adaptive attitudes and decisions; furthermore, benefits of positive affect accumulate by building the trait of resiliency and other kinds of health-sustaining resources (Tugade, Devlin, \& Fredrickson, 2014; Moskowitz \& Saslow, 2014). In contrast, negative affect narrowly focuses the cognitive process and behavioral tendencies on the aim of overcoming current adversities, but when experienced intensely and frequently it can have deleterious health consequences such as depression, anxiety, harmful coping habits, immune deficiencies, chronic physical health conditions and increased risk of mortality (Smith \& Ascough, 2016). In fact, the harms of negative emotions are proven to be more powerful than the profits of positive emotions (Rozin \& Royzman, 2001). However, taking the functional specialization of positive and negative emotion into account, both are considered necessary. So the evaluation of valence parameters refers not only to the frequency and intensity of experiencing positive and negative emotions, but also to the ratio of positive to negative emotions, with empirically established optimal values ranging approximately from 3:0 to 5:0 (Fredrickson, 2013). Another valence-related parameter of emotional health is the co-activation of positive and negative affects, known as mixed emotions (Larsen \& McGraw, 2014), dialectical emotions (Wilken \& Miyamoto, in press) or emotional complexity (Grossmann, Huynh, \& Ellsworth, 2016). We do not know yet the exact impact of affective co-activation on health (Wilken \& Miyamoto, in press), but mixed emotional experiences are considered to be a vital part of emotional health characteristics since there are data demonstrating their contribution to cognitive procesing (van Harreveld, Rutjens, Schneider, Nohlen, \& Keskinis, 2014) and resilience (Braniecka, Trzebińska, Dowgiert, \& Wytykowska, 2014) as well as their considerable frequency and individual differences (Watson \& Stanton, 2017).

Emotion regulation. Regulation of emotions encompasses a multitude of processes that serve to reduce, sustain, amplify or change in any other way one or more aspects of emotional processing (Werner \& Gross, 2010). People usually attempt to decrease negative emotions, to increase positive emotions, or - to a lesser extent - vice versa; they also sometimes try to change one emotion (e.g. fear) into another (e.g. anger). Emotion regulation which is unsuccessful with respect to the regulatory goals or because of resulting harms is considered maladaptive. An evaluation of the particular regulatory acts requires a great deal of thoroughness (Costa Martins, Freire, \& Ferreira-Santos, 2016). Certain regulatory operations are generally regarded as obviously hurtful 
(e.g. substance use or self-injury), while others are proven to be essentially disadvantageous (e.g. suppression) or essentially beneficial (e.g. cognitive positive reappraisal, humor or acceptance); however, the context of individual dispositions and momentary circumstances has to be carefully examined (Gross, 2013). There are some special health-related regulatory problems, such as the ways and magnitude of amplification of positive emotions (Dillon \& Pizzagalli, 2010), the scope of regulatory flexibility (Aldao, Sheppes, \& Gross, 2015), or the side-effects of emotion regulation for emotional processing, e.g. emotion's coherence (Dan-Glauser \& Gross, 2013). Since emotion regulation is considered to be a meta-valuation process (Suri \& Gross, 2016), its health effects also depend on the type of meta-emotions arising in consequence of experienced emotion (Shaver, Veilleux, \& Ham, 2013), the level of extremity of emotion-oriented valuation standards such as the "should" affect or the "ideal" affect (Thompson, Kircanski, \& Gotlib, 2016) or the rules governing the individual's choice between different emotion regulation strategies (Sheppes et al., 2014).

Dynamic of emotional processing. Emotion is a multi-componential transitional process consisting of affective, motivational, cognitive, somatic, motor and subjective phenomena (Moors \& Scherer, 2013). During an emotional episode, aspects of an event are simultaneously appraised in a series of modifications in each of those subsystems, and the processing will stop when synchronization of different subsystems and a conclusive result are achieved (Grandjean, Sander, \& Scherer, 2008). The coherence of emotions is a prerequisite of healthy functioning (Barrett, 2015 ), as can be seen when integrative processes fail, e.g. under suppression (Dan-Glauser \& Gross, 2013) or in the case of emotional dissonance (Indregard, Knardahl, \& Nielsen, 2017). Another dynamic characteristic of emotion is its duration. The longer time of emotion's generation is characteristic of more mature and complex affective responses (Trzebińska, 2012), while the extended lasting of emotion activation after the termination of the eliciting stimulation results in the interruption of its informative function and permanent stress production (Mechelen, Verduyn, \& Brans, 2013), particularly in the case of traumatic events (Ruden 2011). The intensity of emotion or its specific components is also a well-known dimension of the emotional dynamic related to health, e.g. intense hostility in the etiology of coronary heart disease, extremely low positive emotions as a predictor of depression, diminished expression in the course of schizophrenia, high anxiety in obsessive-compulsive disorder, or extremely intense alternately hate and love in borderline personality disorder (Kubzansky \& Winning, 2016; Kring \& Mote, 2016).

Occurrence of discrete emotions. In spite of the widely accepted assumption that all emotions are functional, it has to be emphasized that they differ with regard to health effects: some emotions (e.g. panic, hate or hostility) are apparently malignant, some (e.g. disgust, shame or jealousy) can be hazardous, and some (e.g. hope, gratitude, compassion, love) enhance well-being generally (Cheavens \& Ritschel, 2014; Tangney \& Salovey, 2010; Consedine, 2008; DeSteno, Condon, \& Dickens, 2016; Diamond, 2014; Cassiello-Robbins \& Barlow, 2016). On the other hand, emodiversity, i.e. the amount of discrete emotions that are experienced and the extent to which specific emotions are experienced in the same proportion (regardless of whether they are positive, negative, or mixed), was proven to be associated with better mental and physical health as a base of emotional flexibility and protection against the dominance of detrimental emotions, such as acute fear, anger, or sadness (Quoidbach et al., 2014).

Understanding and articulation of emotion. The conscious feeling, i.e. subjective experience of emotion, is a special component of emotion which serves a monitoring function (Grandjean, Sander, \& Scherer, 2008). The feeling is an extraordinarily complex conglomerate of information from different emotional systems, but nevertheless it overlaps just a small part of emotional processing. Routine selectivity of emotional components in feelings in the form of underrepresentation of the affective component together with overrepresentation of bodily and behavioral components is a characteristic affective feature in personality disorders (Trzebińska \& Gabińska, 2014). The general quality of the cognitive representation of emotions is a foundation of emotional intelligence (Brackett, Rivers, \& Bertoli, 2016), while its different facets are addressed explicitly by such dimensions as emotional clarity, i.e. general knowledge of own emotions, and emotion differentiation (also known as emotion granularity), i.e. the ability to distinguish momentary experienced emotions (e.g., anger vs. fear) into discrete categories (Boden, Thompson, Dizén, Berenbaum, \& Baker, 2013).

Personal disposition and practices concerning emotions. There is a multitude of personality traits associated with proneness to the experience of a particular kind of discrete emotions (such as the trait of anxiety, the trait of gratitude, the trait of love or the trait of curiosity), which promote their occurrence and functionality (Peterson, \& Seligman 2004). There are also personality traits associated with general reactivity to the signs of reward or $=$ threat (i.e. with proneness to experience positive and negative emotions); among them extraversion and neuroticism are proven to have the most clear (respectively) favorable and unfavorable effects on health (McAdams, 2016; Komulainen et al., 2014). Individual differences in the regularity of practicing in everyday life of the prioritizing positivity (i.e. an active search for happiness by seeking and organizing circumstances 
that can give raise to positive emotions, as opposed to just wanting to be happy) predicts more well-being and less psychopathology (Catalino, Algoe, \& Fredrickson, 2014). The other health-related dispositions influencing emotions indirectly as a base of emotion regulation are: attitudes towards emotions (Harmon-Jones, Harmon-Jones, Amodio, \& Gable, 2011), affective metacognitions (Beer \& Moneta, 2012) and coherence-based reasoning (Simon, Stenstrom, \& Read, 2015).

Social facets of emotions. Emotions influence health via the mechanisms of social communication and participation, which fulfill the needs for affiliation, social distancing and social exchange as a main concern (Fischer \& Manstead, 2016). Accordingly, such social-emotional competencies as empathy (i.e. the ability and tendency to co-experience and comprehend emotional experience of other people; Zaki \& Ochsner, 2016), intimacy (i.e. the ability to form and maintain mutually close and positive relationships; Eisenberg, 2016) and self-disclosure (i.e. the ability and tendency to share own emotions with other people; Sloan, 2010) serve as prerequisites for health. Based on the growing data on cultural differences in learning, generating, regulating, experiencing and expressing emotions (Mesquita, De Leersnyder, \& Boiger, 2016), the cultural aptness of emotional processing comes into view as one more well-being related social-emotional competence.

\section{CONCLUSION}

The transdiagnostic approach and the integration of psychotherapy share the same concern about finding common ground for the psychological practice in the domain of health. The presented emotional health notion can serve as an umbrella concept helping to take full advantage of affective science in order to unite the effort of that movement in providing tools for assessing, explaining and fixing health problems related to affective deficiencies in clinical practice, as well as for preventive strengthening of the emotional competency in childcare and social relationships.

There are tremendous advances in the theory and research on emotional processing. We have gained a detailed understanding of neuroanatomic, genetic, mental and environmental principles of emotion generation and regulation, as well as the bio-psychological nature of the state of emotion. It is also proven that the quality of emotions is one of the most influential factors of mental and physical well-being (Pressman, Gallagher, \& Lopez, 2013; Kring \& Mote, 2016; Consdine, 2018). The dynamic and multifaceted nature of emotional processing and its maturation allow comprehensive dimensional characterization of emotions, since there is no sharp division between positive and negative emotion, primary and complex emotion, adaptive and maladaptive emotion regula- tion and so on (Barrett, 2009). As all emotional attributes are empirically identified, the appropriate measures are available and - in many cases - approximate optimal values are known. Thus, in line with the RDoC approach, the emotional health concept serves to evaluate the level of mental and physical health-related emotional variables rather than to diagnose whether the psychopathology occurs or does not occur; however, knowing optimal values of those variables, severity of the abnormality can be assessed as well. Applications of the emotional health concept in psychotherapy can help to target interventions on specific emotional deficiencies and set therapeutic goals as concrete, meticulously chosen forms or levels of emotional processing. The proposed common psychotherapy factors can be straightforwardly included in the emotional health concept as most of them are the same as the mental health parameters (e.g. emotion regulation or empathy) and some can be adequately accommodated by means of redefinition (e.g. catharsis into an expressive component of emotional processing). On the other hand, the data on emotional health parameters can inspire further search for common factors in psychotherapy.

The current notion of emotional health has some limitations that have to be mentioned as well. First, for now it contains the categorization of health-related parameters with relatively little information about their interrelation and optimal values. Affective science gathers much more data on which aspects of emotionality are important from the health perspective than on their interplay. Much more effort is undertaken to identify new health relevant variables than on establishing optimal values and significant irregularities of those already known. Second, there is difficulty concerning the large number of emotional agents of the physical and mental health outcomes. Each of the above categories of emotional health consists of numerous parameters, and it seems uneconomical, maybe even impossible or inappropriate, to apply all of them in every case. Thus practitioners will need some well-grounded and detailed guidelines on how to decide which parameters of emotional health to measure in diagnosis and address in intervention. The rules of choice of the emotional health parameters for case conceptualization and psychotherapy planning is one more problem to be resolved in the future. Third, in the research on health-related aspects of emotional processing, health is defined predominantly in the traditional terms of normality-abnormality, specific symptoms and disorders presence-absence, leaving aside many other facets of human distress and flourishing (Kring \& Mote, 2016). Lastly, as emotional health is just one of many domains of health-related processes, it needs to be advisedly introduced into emerging comprehensive models of multimodal mechanisms underlying mental and physical well-being. 


\section{REFERENCES}

Achenbach, T. M., \& Edelbrock, C. S. (1978). The classification of child psychopathology: A review and analysis of empirical efforts. Psychological Bulletin, 85, 1275-1301.

Aldao, A., Sheppes, G., \& Gross, J. J. (2015). Emotion Regulation Flexibility. Cognitive Therapy \& Research, 39, 263-278. doi: 10.1007/s10608-014-9662-4

Barrett, L. F. (2005). Feeling is Perceiving: Core Affect and Conceptualization in the Experience of Emotion. In L. F. Barrett, P. N. Niedenthal, \& P. Winkielman (eds.), Emotion and Consciousness (pp. 255-284). New York: The Guilford Press.

Barrett, L. F. (2009). The Future of Psychology: Connecting Mind to Brain. Perspectives on Psychological Science, 4, 326-339. doi: 10.1111/j.17456924.2009.01134.x

Barrett, L. F. (2015). Ten Common Misconceptions about Psychological Construction Theories of Emotions. In L. F. Barrett, \& J. A. Russell (eds.), The Psychological Construction of Emotion (pp. 45-79). New York: The Guilford Press.

Beer, N., \& Moneta, G. B. (2012). Coping and Perceived Stress as a Function of Positive Metacognitions and Positive Meta-Emotions. Individual Differences Research, 10, 105-116.

Boden, M.T., Thompson, R. J., Dizén, M., Berenbaum, H., \& Baker, J. P. (2013). Are emotional clarity and emotion differentiation related? Cognition and Emotion, 27, 961-978. doi: org/10.1080/02699931.2 012.751899

Brackett, M. A., Rivers, S. E., \& Bertoli, M. C. (2016). Emotional Intelligence. In L. F. Barrett, M. Lewis, \& J. M. Haviland-Jones (eds.), Handbook of Emotions. Fourth Edition (pp. 513-531). New York: The Guilford Press.

Braniecka, A., Trzebinska, E., Dowgiert, A., \& Wytykowska, A. (2014). Mixed emotions and coping: The benefits of secondary emotions. PloS One, 9, e103940. doi:10.1371/journal.pone.0103940

Brown, J. (2015). Specific Techniques vs. Common Factors? Psychotherapy Integration and its Role in Ethical Practice. American Journal of Psychotherapy, 69, 301-316.

Brown, M., Larson, J., Harper, J., \& Holman, T. (2016). Family-of-origin experience and emotional health as predictors of relationship self-regulation in marriage. Journal of Family Therapy, 38, 319-339. doi: 10.1111/1467-6427.12066

Cassiello-Robbins, C., \& Barlow, D. H. (2016). Anger: The Unrecognized Emotion in Emotional Disorders. Clinical Psychology: Science and Practice, 23, 1, 66-85. doi: 10.1111/cpsp.12139

Catalino, L. I, Algoe, S. B., \& Fredrickson, B. L. (2014). Proritizing Positivity: An Effective Approach to Pursuing Happiness? Emotion, 14, 1155-1161. doi: org.10.1037/a0038029
Cheavens, J. S., \& Ritschel, L. A. (2014). Hope Theory. In M. M. Tugade, M. N. Shiota, \& L. D. Kirby (eds.), Handbook of Positive Psychology (pp. 396-410). New York: The Guilford Press.

Clark-Polner, E., Wager, T. D., Satpute, A. B., \& Barrett, L. F. (2016). Neural Fingerprinting: Meta-Analysis, Variation, and the Search. In L. F. Barrett, M. Lewis, \& J. M. Haviland-Jones (eds.), Handbook of Emotions. Fourth Edition (pp. 146-165). New York: The Guilford Press.

Clore, G. L., \& Robinson, M. D. (2012). Five New Ideas About Emotions and Their Implication for Social-Personality Psychology. In K. Deux, \& M. Snyder (eds.), The Oxford Handbook of Social Psychology (pp. 315-336). New York: Oxford University Press.

Consdine, N. S. (2008). Health Promoting and Health-Demaging Effects of Emotions. In M. Lewis, J. M. Haviland-Jones, \& L. F. Barrett (eds.), Handbook of Emotions. Third Edition (pp. 676-690). New York: The Guilford Press.

Costa Martins, E., Freire, M., \& Ferreira-Santos, F. (2016). Examination of Adaptive and Maladaptive Cognitive Emotion Regulation Strategies as Transdiagnostic Processes: Associations with Diverse Psychological Symptoms in College Students, Studia Psychologica, 58, 1, 59-73.

Cuthbert, B. N. (2014). The RDoC framework: facilitating transition from ICD/DSM to dimensional approaches that integrate neuroscience and psychopathology. World Psychiatry, 13, 1, 28-35. doi: 10.1002/wps.20087

Dan-Glauser, E. S., \& Gross, J. J. (2013). Emotion Regulation and Emotion Coherence: Evidence for Strategy-Specific Effects. Emotion, 13, 832-842. doi: $10.1037 / \mathrm{a} 0032672$

DeSteno, D., Condon, P., \& Dickens, L. (2016). Gratitude and Compassion. In L. F. Barrett, M. Lewis, \& J. M. Haviland-Jones (eds.), Handbook of Emotions. Fourth Edition (pp. 835-846). New York: The Guilford Press.

DeSteno, D., Gross, J. J., \& Kubzansky, L. (2013). Affective Science and Health: The Importance of Emotion and Emotion Regulation. Health Psychology, 32, 474-486. doi: org/10.1037/a0030259

Diamond, L. M. (2014). Romantic Love. In M. M. Tugade, M. N. Shiota, \& L. D. Kirby (eds.), Handbook of Positive Psychology (pp. 311-328). New York: The Guilford Press.

Dillon, D. G., \& Pizzagalli, D. A. (2010). Maximizing Positive Emotions: A Translational, Transdiagnostic Look at Positive Emotion Regulation. In A. M. Kring, \& D. M. Sloan (eds.), Emotion Regulation and Psychopathology: A Transdiagnostic Approach to Etiology and Treatment (pp. 229-252). New York: The Gulford Press.

Eaton, N. R., Rodriguez-Seijas, C., Carragher, N., \& Krueger, R. F. (2015). Transdiagnostic factors of 
psychopathology and substance use disorders: a review. Social Psychiatry and Psychiatric Epidemiology, 50, 171-182. doi: 10.1007/s00127-0141001-2

Eisenberger, N. L. (2016). Social Pain and Social Pleasure. Regulation. In L. F. Barrett, M. Lewis, \& J. M. Haviland-Jones (eds.), Handbook of Emotions. Fourth Edition (pp. 440-452). New York: The Guilford Press.

Epstein, S., \& Epstein, M. L. (2016). An Integrative Theory of Psychotherapy: Research and Practice. Journal of Psychotherapy Integration, 26, 116-128. doi: org/10.1037/int0000032

Fisher, A. H., \& Manstead, A. S. R. (2016). Social Function of Emotion and Emotion Regulation. In L. F. Barrett, M. Lewis, \& J. M. Haviland-Jones (eds.), Handbook of Emotions. Fourth Edition (pp. 424-439). New York: The Guilford Press.

Fredrickson, B. L. (2013). Updated Thinking on Positivity Ratios. American Psychologist, 68, 814-822. doi: 10.1037/a0033584

Fernández-Álvarez, H., Consoli, A. J., \& Gómez, B. (2016). Integration in Psychotherapy: Reasons and Challenges. American Psychologist, 71, 820830. doi: org/10.1037/amp0000100

Frijda, N. H. (2008). The Psychologist's Point of View. In M. Lewis, J. M. Haviland-Jones, \& L. F. Barrett (eds.), Handbook of Emotions. Third Edition (pp. 68-87). New York: The Guilford Press.

Gendron, B., Kouremenou, E., \& Rusu, C. (2016). Emotional Capital Development, Positive Psychology and Mindful Teaching: Which Links? The International Journal of Emotional Education, 8, 63-74.

Genzel, B., Rarick, J. R. D., \& Morris, P. A. (2016). Stress and Emotion: Embodied, in Context, and across the Lifespan. In L. F. Barrett, M. Lewis, \& J. M. Haviland-Jones (eds.), Handbook of Emotions. Fourth Edition (pp. 707-735). New York: The Guilford Press.

Grandjean, D., Sander, D., \& Scherer, K. R. (2008). Conscious emotional experience emerges as a function of multilevel, appraisal-driven response synchronization. Consciousness and Cognition, 17, 484-495.

Gross, J. J. (2013). Emotion Regulation: Taking Stock and Moving Forward. Emotion, 13, 359-365. doi: 10.1037/a0032135

Grossmann, I., Huynh, A. C., \& Ellsworth, P. C. (2016). Emotional Complexity: Clarifying Definitions and Cultural Correlates. Journal of Personality and Social Psychology, 111, 895-916. doi: org/10.1037/ pspp0000084

Harmon-Jones, E., Harmon-Jones, C., Amodio, D. M., \& Gable, P. A. (2011). Attitudes Toward Emotions. Journal of Personality and Social Psychology, 101, 1332-1350. doi: 10.1037/a0024951

Harvey, A., Watkins, E., Mansell, W., \& Shafran, R. (2004). Cognitive behavioural processes across psy- chological disorders: a transdiagnostic approach to research and treatment. Oxford: Oxford University Press.

Hofmann, S. G. (2016). Emotion in Therapy. From Science to Practice. New York: The Guilford Press.

Indregard, A. M., Knardahl, S., \& Nielsen, M. (2017). Emotional dissonance and sickness absence: a prospective study of employees working with clients. International Archives of Occupational \& Environmental Health, 90, 83-92.

Komulainen, E., Meskanen, K., Lipsanen, J., Lahti, J. M., Jylha, P., Melartin, T., ..., et al. (2014). The Effect of Personality on Daily Life Emotional Processes. PLoS One, 9, e110907. doi:10.1371/journal. pone.0110907

Kring, A. M., \& Mote, J. (2016). Emotion Disturbances as Transdiagnosic Processes In Psychopathology. In L. F. Barrett, M. Lewis, \& J. M. Haviland-Jones (eds.), Handbook of Emotions. Fourth Edition (pp. 653-669). New York: The Guilford Press.

Kubzansky, L. D., \& Winning, A. (2016). Emotions and Health. In L. F. Barrett, M. Lewis, \& J. M. HavilandJones (eds.), Handbook of Emotions. Fourth Edition (pp. 613-633). New York: The Guilford Press.

Lambert, M. J., \& Ogles, B. M. (2014). Common Factors: Post Hoc Explanation or Empirically Based Therapy Approach? Psychotherapy, 51, 500-504. doi: $10.1037 / \mathrm{a} 0036580$

Laska, K. M., Gurman, A. S., \& Wampold, B. M. (2014). Expanding the Lens of Evidence-Based Practice in Psychotherapy: A Common Factors Perspective. Psychotherapy, 51, 467-481. doi: 10.1037/a0034332

Larsen, J. T., \& McGraw, A. P. (2014). The Case for Mixed Emotions. Social and Personality Psychology Compass 8/6, 263-274. doi: 10.1111/spc3.12108

Lewis, M. (2016). The Emergence of Human Emotions. In L. F. Barrett, M. Lewis, \& J. M. HavilandJones (eds.), Handbook of Emotions. Fourth Edition (pp. 272-292). New York: The Guilford Press.

McAdams, D. P. (2016). The Art and Science of Personality Development. New York: The Guilford Press.

Mechelen, I. V., Verduyn, P., \& Brans, K. (2013). A duration of emotional episodes. In D. Hermans, B. Rimé, \& B. Mesquita (eds.), Changing emotions (pp. 174-180). London: Psychology Press.

Mernitz, S. E., \& Kamp Dush, C. (2015). Emotional Health Across the Transition to First and Second Unions Among Emerging Adults. Journal of Family Psychology, 30, 233-244. doi: org/10.1037/ fam0000159

Mesquita, B., de Leersnyder, J., \& Boiger, M. (2016). The Cultural Psychology of Emotions. In L. F. Barrett, M. Lewis, \& J. M. Haviland-Jones (eds.), Handbook of Emotions. Fourth Edition (pp. 393441). New York: The Guilford Press.

Moors, A., \& Scherer, K. R. (2013). The Role of Appraisal in Emotions. In M. D. Robinson, E. R. Watkins, \& Harmon-Jones, E. (eds.), Handbook of Cog- 
nition and Emotions (pp. 135-155). New York: The Guilford Press.

Moskowitz, J. T., \& Saslow, L. R. (2014). Health and Psychology: The Importance of Positive Affect. In M. M. Tugade, M. N. Shiota, \& L. D. Kirby (eds.), Handbook of Positive Psychology (pp. 413-431). New York: The Guilford Press.

Nikolova, Y. S., Davis, E. G., \& Hariri, A. R. (2016). Genetic Contributions to Affect and Emotions. In L. F. Barrett, M. Lewis, \& J. M. Haviland-Jones (eds.), Handbook of Emotions. Fourth Edition (pp. 182-198). New York: The Guilford Press.

Nolen-Hoeksema, S., \& Watkins, E. R. (2011). A Heuristic for Developing Transdiagnostic Models of Psychopathology: Explaining Multifinality and Divergent Trajectories. Perspectives on Psychological Science, 6, 589-609. doi: 10.1177/1745691611419672

Quoidbach, J., Gruber, J., Mikolajczak, M., Kogan, A. Kotsou, I., \& Norton, M. I. (2014). Emodiversity and the Emotional Ecosystem. Journal of Experimental Psychology: General, 143, 2057-2066. doi: org/10.1037/a0038025

Peterson, C., \& Seligman, M. E. P. (2004). Character strengths and virtues. A handbook and classification. Oxford: Oxford University Press.

Pressman, S. D., Gallagher, M. W., \& Lopez, S. J. (2013). Is the Emotion-Health Connection a "First-World Problem"? Psychological Science, 24, 544-549. doi: 10.1177/0956797612457382

Renshaw, T. L., Eklund, K. R., Bolognino, S. J., \& Adodo, I. (2016). Bidimensional emotional health in college students: A comparison of categorical and continuous analytic approaches. Journal of Psychopathology and Behavioral Assessment, 38, 681-694. doi: org/10.1007/s10862-016-9558-6

Rozin, P., \& Royzman, E. B. (2001). Negativity bias, negativity dominance, and contagion. Personality and Social Psychology Review, 5, 296-320.

Ruden, A. R. (2011). When The Past Is Always Present. Emotional Traumatization, Causes, and Cures. New York: Routledge.

Shaver, J. A., Veilleux, J. C., \& Ham, L. S. (2013). Meta-emotions as Predictors of Drinking Ti Cope: A Comparison of Competing Models. Psychology of Addictive Behaviors, 27, 1019-1026. doi: 10.1037/ a0033999

Sheppes, G., Scheibe, S., Suri, G., Radu, P., Blechert, J., \& Gross, J. J. (2014). Emotion Regulation Choice: A Conceptual Framework and Supporting Evidence. Journal of Experimental Psychology, 143, 163-181. doi: 10.1037/a0030831

Simon, D., Stenstrom, D. M., \& Read, S. J. (2015). The Coherence Effect: Blending Cold and Hot Cognitions. Journal of Personality and Social Psychology, 109, 369-394. doi: org/10.1037/pspa0000029

Sloan, D. (2010). Self-Disclosure and Psychological Well-being. In J. M. Maddux, \& J. P. Tangney (eds.), Social Psychological Foundations of Clinical
Psychology (pp. 212-225). New York: The Guilford Press.

Smith, R. E., \& Ascough, J. C. (2016). Promoting emotional resilience: Cognitive-affective stress management training. New York: Guilford Press.

Suri, G., \& Gross, J. J. (2016). Emotion Regulation: A Valuation Perspective. In Psychopatkology. In L. F. Barrett, M. Lewis, \& J. M. Haviland-Jones (eds.), Handbook of Emotions. Fourth Edition (pp. 453-466). New York: The Guilford Press.

Tangney, J. P., \& Salovey, P. (2010). Emotions of the Imperiled Ego: Shame, Guilt, Jealousy, and Envy. In J. M. Maddux, \& J. P. Tangney (eds.), Social Psychological Foundations of Clinical Psychology (pp. 245-271). New York: The Guilford Press.

Thompson, R. A., \& Winer, A. C. (2013). The Developmental Polyphony of Cognition and Emotions. In M. D. Robinson, E. R. Watkins, \& Harmon-Jones, E. (eds.), Handbook of Cognition and Emotions (pp. 292-311). New York: The Guilford Press.

Thompson, R. J., Kircanski, K., \& Gotlib, I. H. (2016). The Grass Is Not as Green as You Think: Affect Evaluation in People with Internalizing Disorders. Journal of Affective Disorders, 203, 233-240. doi: http://dx.doi.org/10.1016/j.jad.2016.06.006

Tryon, W. W. (2016). Transtheoretic Transdiagnostic Psychotherapy. Journal of Psychotherapy Integration, 26, 273-287. doi: org/10.1037/a0040041

Trzebińska, E. (1998). Dwa wizerunki własnej osoby [Two selves]. Warszawa: Wydawnictwo Instytutu Psychologii PAN.

Trzebińska, E. (2012). W kierunku nauki o zdrowiu emocjonalnym [Towards the science of emotional health]. In H. Szuster, \& D. Karwowska (eds.), W stronę podmiotowości: o emocjonalności, tożsamości i pożytkach z porannego wstawania (pp. 69-84). Sopot: Smak Słowa.

Trzebińska, E., \& Gabińska, A. (2014). Features of Emotional Experiences in Individuals with Personality Disorders. Polish Psychological Bulletin, 45. doi: https://doi.org/10.2478/ppb-2014-0020

Tsai, J. L., \& Park, B. (2014). The Cultural Shaping of Happiness: The Role of Ideal affect. In J. Gruber, \& J. T. Moskowitz (eds.), Positive Emotions. Integrating the Light Sides and Dark Sides (pp. 345-362). Oxford: Oxford University Press.

Tugade, M. M., Devlin, H. C., \& Fredrickson, B. L. (2014). Infusing Positive Emotions into Life: The Broaden-and-Build Theory and a Dual-Process Model of Resilency. In M. M. Tugade, M. N. Shiota, \& L. D. Kirby (eds.), Handbook of Positive Emotions (pp. 28-43). New York: The Guilford Press.

van Harreveld, F., \& Rutjens, B. T., Schneider, I. K., Nohlen, H. U., \& Keskinis, K. (2014). In Doubt and Disorderly: Ambivalence Promotes Compensatory Perceptions of Order. Journal of Experimental Psychology: General, 143, 1666-1676. 
Watson, D., \& Stanton, K. (2017). Emotion Blends and Mixed Emotions in the Hierarchical Structure of Affect. Emotion Review, 1-6. doi: 10.1177/ 1754073916639659

Watson, D., Stanton, K., \& Clark, L. A. (2016). Self-report indicators of negative valence constructs within the research domain criteria (RDoC): A critical review. Journal of Affective Disorders. doi: 10.1016/j.jad.2016.09.065

Werner, K., \& Gross, J. J. (2010). Emotion Regulation and Psychopathology: A Conceptual Framework. In A. M. Krin, \& D. M. Sloan (eds.), Emotion Regulation and Psychopathology: A Transdiagnostic Approach to Etiology and Treatment (pp. 13-37). New York: The Guilford Press.

Wilken, B., \& Miyamoto, Y. (in press). Dialectical Emotions. In J. Spencer-Rodgers \& K. Peng (eds.), Dialectical Thinking.

You, S., Furlong, M., Felix, E., \& O’Malley, M. (2015). Validation of the Social and Emotional Health Survey for Five sociocultural Groups: Multigroup Invariance and Latent Mean Analyses. Psychology in the Schools, 52, 349-362. doi: 10.1002/pits.21828

Zaki, J., \& Ochsner, K. (2016). Empathy. In L. F. Barrett, M. Lewis, \& J. M. Haviland-Jones (eds.), Handbook of Emotions. Fourth Edition (pp. 871884). New York: The Guilford Press. 